УДК 622.831.1

ИССЛЕДОВАНИЕ ИЗМЕНЕНИЙ ГЕОМЕХАНИЧЕСКОГО СОСТОЯНИЯ

МАССИВА ПРИ ВХОДЕ ОЧИСТНЫХ ЗАБОЕВ В ДЕМОНТАЖНЫЕ КАМЕРЫ ПО ПЛАСТУ «БАЙКАИМСКИЙ» ШАХТЫ ИМ. «7 НОЯБРЯ» АО «СУЭК-КУЗБАСС»

\title{
STUDY OF CHANGES IN THE GEOMECHANICAL CONDITION OF THE ROCK STRATA WHEN A PRODUCTION FACE ENTERS A DISMANTLING CHAMBER IN SEAM "BAJKAIMSKY" OF 7TH NOVEMBER MINE, JSC "SUEK-KUZBASS"
}

Торро Виктор Оскарович, ст. преподаватель е-mail: torrovo@mail.ru

Victor O. Torro, Senior lecturer Ремезов Анатолий Владимирович, д.т.н. проф. кафедры ГМиК, е-mail: lion742@mail.ru Anatoly V. Remezov, Dr. Sc. (Engineering), Professor

Кузбасский государственный технический университет имени Т.Ф. Горбачева. Россия, 650000, г. Кемерово, ул. Весенняя, 28

T.F. Gorbachev Kuzbass State Technical University, 28 street Vesennyaya, Kemerovo, 650000, Russian Federation

Аннотация: Существенной проблемой, влияющей на снижение объёмов добычи из очистных механизированных забоев, оборудованных механизированными комплексами, являются существуюшие сроки перемонтажа их оборудования. Например, продолжительность перемонтажей очистных механизиро-

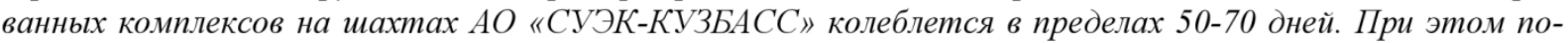
тери добычи составляют 800000 тонн и более. Одним из способов решения этой проблемы является предварительная подготовка демонтажной камеры.

Исследования, ход и результаты которых отражены в данной статье, ставили своей целью определить наиболее эффективный способ предварительной подготовки демонтажной камеры в конкретных условиях.

Для этого были выполнены работы по исследованию геомеханического состояния массива при входе очистных забоев в демонтажную камеру, выполненные по пласту "Байкаимскому» иахты имени "7 ноября» АО «СУЭК-КУЗБАСС». Они состоят в определении:

1. Величин вертикальных смещений пород кровли и почвы в выработках вынимаемого столба;

2. Интенсивности образования куполов.

В итоге сделан ряд выводов, в частности:

1. Формирование демонтажной камеры очистным забоем является наиболее благоприятным вариантом её подготовки;

2. Для более точного определения шага обрушения кровли и нагрузки на перекрытия секций необходимо оснащать все приобретаемые механизированные комплексы автоматизированной системой контроля воздействия горного давления на элементы крепи.

Результаты исследований позволяют сделать правильный выбор способа подготовки демонтажной камеры, что даёт возможность сократить сроки демонтажа оборудования, и тем самым будет способствовать росту объёмов добычи.

Ключевые слова: демонтажная камера, демонтаж оборудования, геомеханическое состояние массива, вертикальные смещения пород, образование куполов, глубина заложения выработки, горное давление, опорное давление, зона повышенного горного давления. 
Abstract: A significant problem affecting the reduction of output from production faces equipped with mechanized complexes, is the existing time for re-installation of their equipment. For example, the duration of re-installation of a set of longwall mining equipment at the mines of JSC SUEK-KUZBASS ranges from 50-70 days. Meanwhile, production losses are 800,000 tons or more. One of the ways to solve this problem is preliminary preparation of the dismantling chamber.

The studies, the course and the results of which are reflected in this article were aimed at determining the most effective way of preliminary preparation of the dismantling chamber in specific conditions.

To this end, work was carried out on the study of the geomechanical state of the rock strata at the entrance of the production faces into the dismantling chamber in seam "Bajkaimsky" of the " $7^{\text {th }}$ November" mine, JSC SUEK-KUZBASS. The work included as follows: lar;

1. Values of vertical displacement of roof and floor rock strata soil in the mine workings of the extracted pil-

2. Intensity of formation of domes.

As a result, some conclusions have been made, including:

1. Formation of the dismantling chamber by a production face is the most favourable option of its preparation;

2. For a more exact determination of roof caving increment and loading on powered support canopies, it is necessary to equip all purchased powered systems with the automated monitoring system for control of rock pressure impact on the support components.

Results of researches allow us to select a correct method of the dismantling chamber preparation that offers the chance to reduce the time of equipment disassembly, and consequently, promote growth of extraction volumes.

Key words: dismantling chamber, equipment dismantle, a geomechanical condition of rock strata, vertical displacement of rock, formation of domes, depth of a mine working abutment pressure, a zone of increased rock pressure. development, a rock pressure,

Продолжительность перемонтажей очистных механизированных комплексов на шахтах ОАО «СУЗК-КУЗБАСС» колеблется в пределах 50-70 дней. При этом потери добычи составляют 800000 т и более. Одним из способов решения этой проблемы является предварительная подготовка демонтажной камеры (ДК). Значительный опыт подготовки ДК различными способами по пласту «Байкаимский» накоплен на шахте имени «7 Ноября» ОАО «СУЭК-Кузбасс» [7,8,10,11]. Мощность пласта «Байкаимский» в среднем составляет 4,6м. Пласт имеет ложную кровлю мощностью 0,3-0,6м, представленную алевролитом с коэффициентом крепости по шкале М.М. Протодъяконова $f=3$ и пределом прочности на одноосное сжатие $\sigma_{\text {сж }}=30$ МПа, склонную к обрушению вслед за выемкой угля. Непосредственная кровля пласта сложена алевролитом, мощностью от 0 до 14 м, $f=$ $4-5, \sigma_{\text {сж }}=40-50$ Мпа, она определяется от среднеустойчивой до неустойчивой. Мощность основной кровли составляет до 76 метров. Она сложена песчаником, $f=8-9, \quad \sigma_{\text {сж }}=80-90$ МПа, труднообрушаемым. Непосредственная почва представлена алевролитом мощностью 8-12м, $f=3-4, \sigma_{\text {сж }}=30$ 40 МПа, средней устойчивости, с сопротивлением вдавливанию 3,0-4,0 МПа. Глубина ведения работ варьируется от 150 до 290 м.

Величина смещений в почве и кровле в/ш 1324, мм

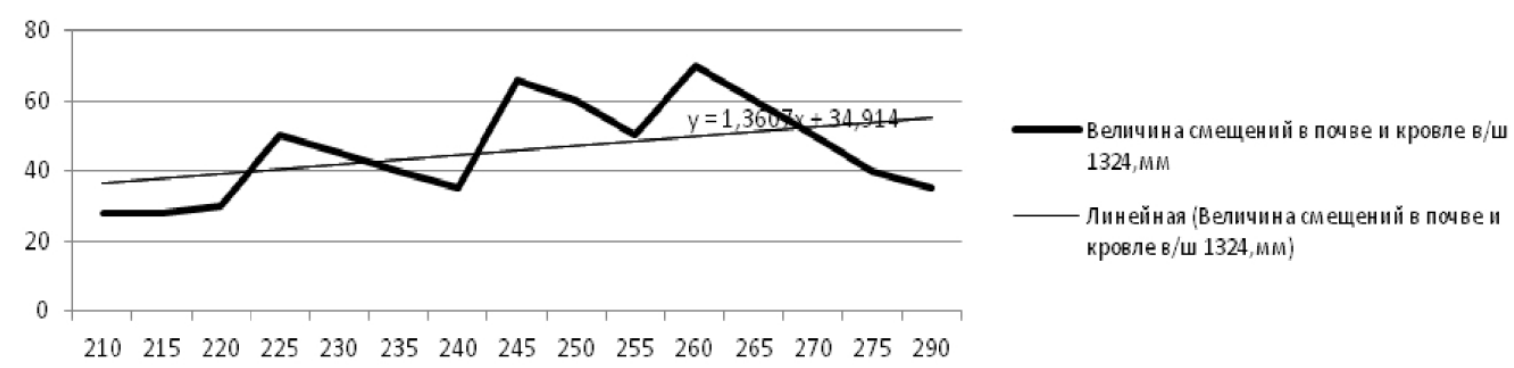

Рис.1. График проявления вертикальньх смещений на в/и №1324 при изменении глубины заложения выработки от 210 м до 290 м. Угол падения от 2- $5^{\circ}$

Fig. 1. The scheme of vertical displacement at air gate No.1324 at a change of the depth of the gate development from $210 \mathrm{~m}$ to $290 \mathrm{~m}$. The angle of seam inclination is 2 to $5^{\circ}$ 


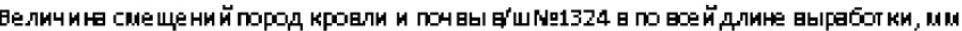
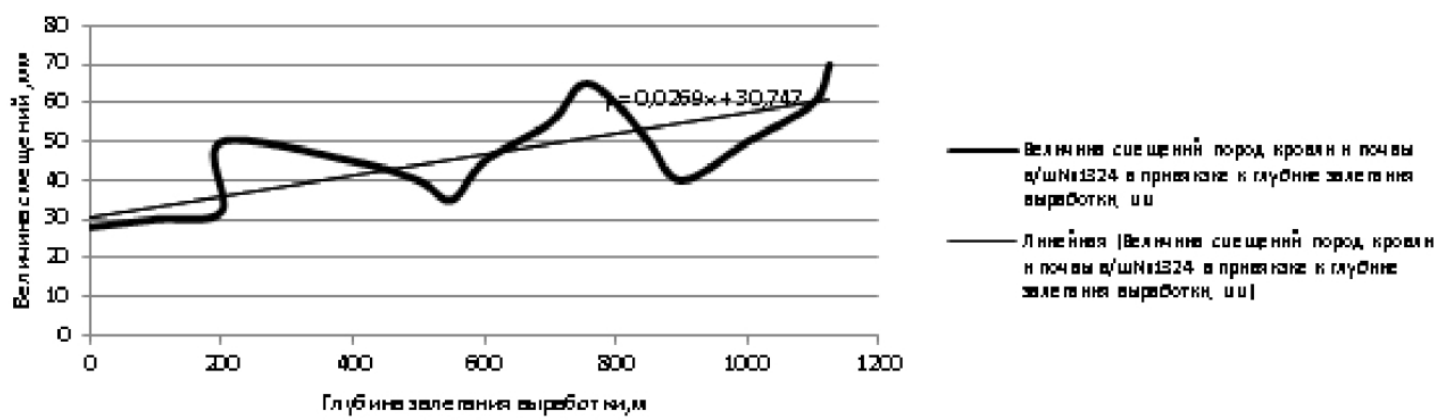

Рис.2. График проявления вертикальных смещений в кровле и почве по всей длине вентиляционного итрека №1324. Угол падения от 2- $5^{\circ}$

Fig. 2. The scheme of vertical displacement in the roof and floor along the length of air gate No.1324. The angle of seam inclination is 2 to $5^{\circ}$

Исследования заключаются в определении вертикальных смещений пород кровли и почвы в оконтуривающих выработках и распределении образования куполов (куполообразования) по длине демонтажной камеры [1-6,9,12-15].

1. Демонтажная камера № 1324

В ходе перемещения мехкомплекса в ДК породы кровли опустились на 1,0-2,5 м по всей длине ДК, за исключением участков длиной 25-30 м, примыкающих к конвейерному и вентиляционному штрекам. Монорельсовая дорога была выведена из строя. В результате продолжительность перемонтажа составила 68 дней.

График проявления вертикальных смещений пород кровли и почвы на в/ш № 1324 в зависимости от глубины заложения выработки отображен на рис. 1.

Анализ графика показывает знакопеременный характер проявления горного давления, однако величина смещений невелика - (40-70) мм поскольку вмещающие породы представлены устойчивыми и среднеустойчивыми образованиями.
.Величина смещений пород кровли и почвы в/ш №1324 по всей длине выработки отображена на рис. 2.

Анализируя график (рис. 3) можно сделать вывод, что они не превышали критических величин и находились в диапазоне 28-70 мм.

Распределение куполообразования по длине демонтажной камеры № 1324 от в/ш № 1324, угол падения $1^{\circ}$ отображено на рис. 3 .

Анализ графиков (рис. 1,2,3) и рассчитанных зависимостей проявления опорного давления $(1,2$, 3) $[1,2,3,9,12,13]$ :

$$
\begin{aligned}
& \sigma=1,36 x+34.91, \\
& \sigma=2,004 x+30,15, \\
& \sigma=33,89 x+1441,
\end{aligned}
$$

позволяет сделать вывод, что в выемочном столбе, на штреках и в демонтажной камере горное давление имело знакопеременный характер. Кроме того, была выявлена тенденция к его повышению с увеличением глубины залегания пласта и в связи с наличием значительных площадей ЗПГД. Всё это приводило к крупноблочному обрушению пород кровли в демонтажной камере №

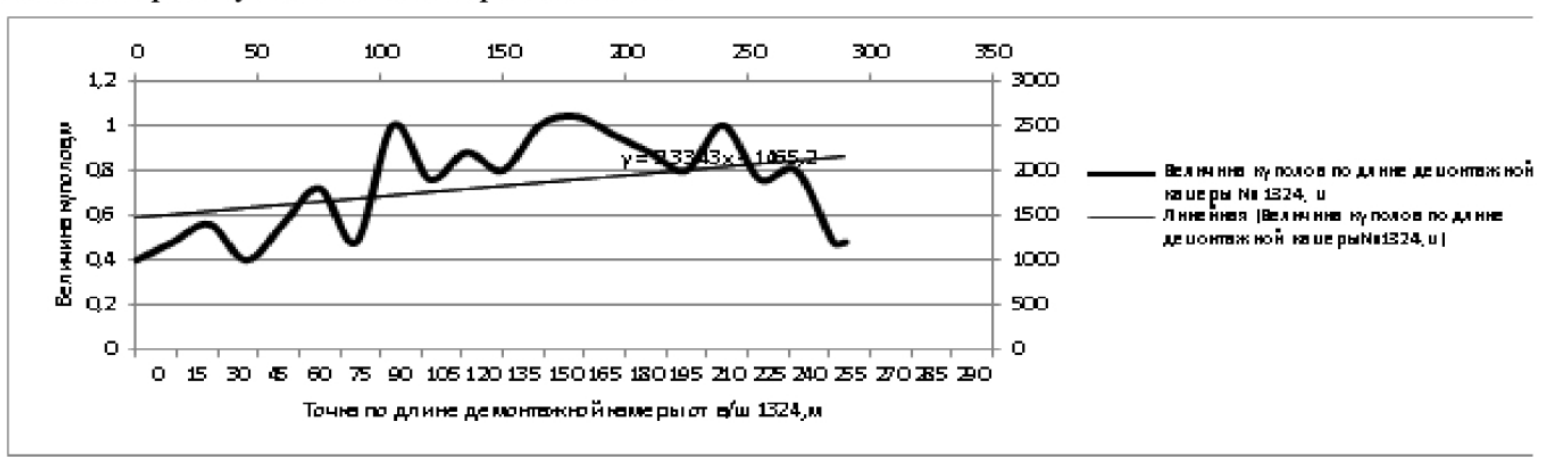

Рис.3. Распределение образования куполов по длине демонтажной камеры № 1324 от в/u № 1324. Угол падения $1^{\circ}$

Fig. 3. Distribution of dome formation along the length of dismantling chamber No. 1324 from air gate No. 1324. The angle of inclination is $1^{\circ}$ 
Величина смещений пород кровли и почвы к/ш №1325 в по всей длине выработки, мм

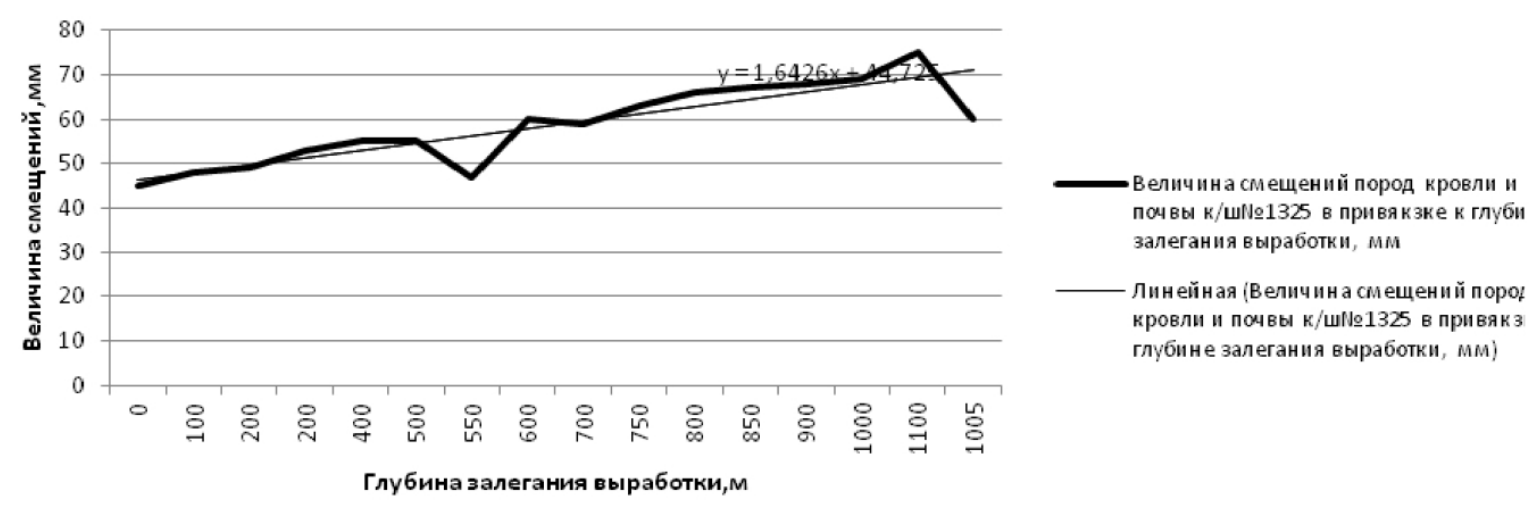

Рис.5. График проявления вертикальных смещений в кровле и почве по всей длине конвейерного штрека №1325. Угол падения от 2-4은

Fig. 5. The scheme of vertical displacement in the roof and floor along the length of conveyor gate No.1325. The angle of seam inclination is 2 to $4^{\circ}$

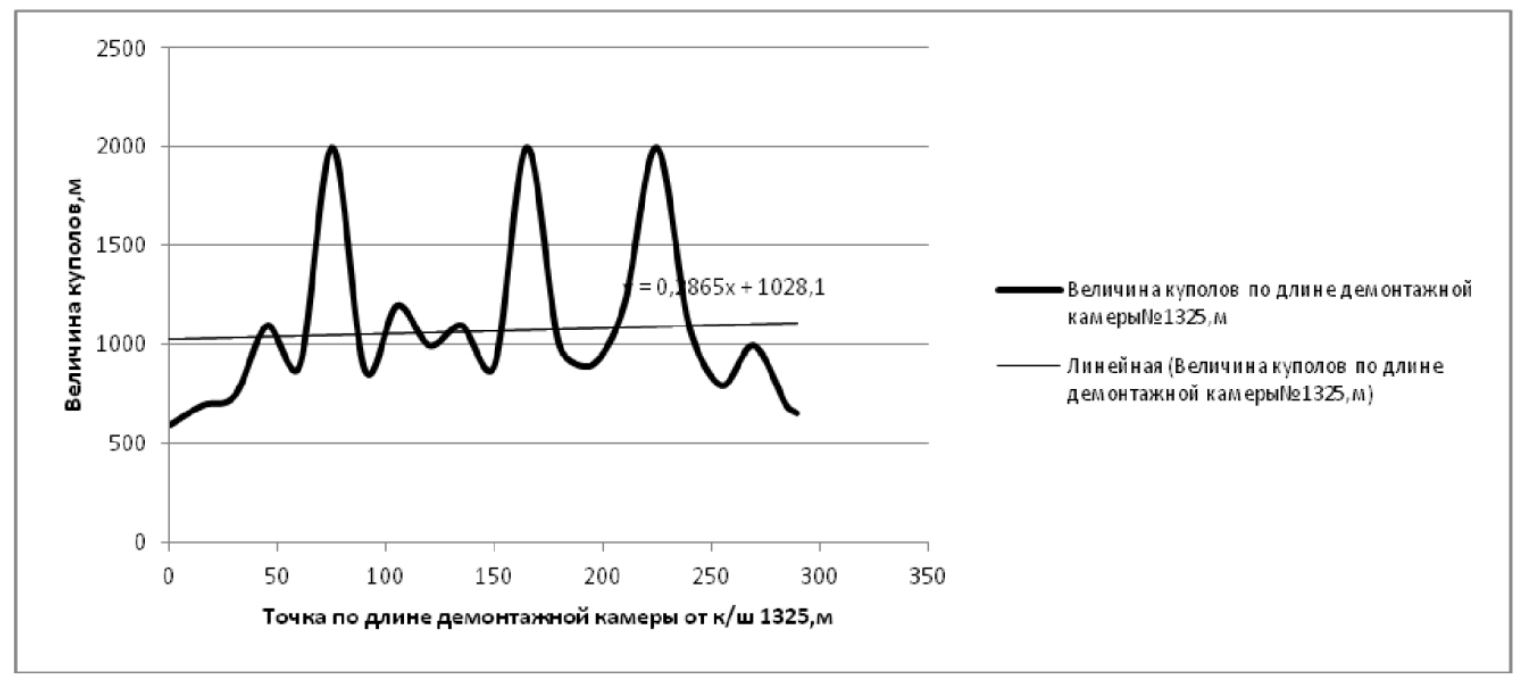

Рис.6.Распределение образования куполов по длине демонтажной камеры № 1325 от конвейерного итрека № 1325. Угол падения $2^{\circ}$

Fig. 6. Distribution of dome formation along the length of dismantling chamber No.1325 from conveyor gate No. 1325. The angle of inclination is $2^{\circ}$

1324.

\section{2. Демонтажная камера №1325}

Следует отметить, что при ведении демонтажных работ происходили вывалы породы. Они носили локальный характер. Высота куполов не превышала 2,0м. Это свидетельствует об устойчивом состоянии приконтурного массива и незначительном расслоении пород непосредственной кровли.

График вертикальных смещений пород кровли и почвы на к/ш №1325 в зависимости от глубины заложения выработки изображен на (рис.4).

Анализируя данный график можно сделать вывод, что смещения не превышали критических величин и находились в диапазоне 28-70 мм. Их увеличение происходит в зонах ПГД и снижаются в зонах разгрузки.

Распределение куполообразования по длине демонтажной камеры № 1325 от к/ш № 1325, угол падения $2^{\circ}$. отображено на рис. 6.

Куполообразование носило эпизодический характер. Высота куполов не превышала 2 м.

Анализ графиков (рис. 4,5,6) и рассчитанных зависимостей проявления опорного давления формулы $(4,5,6)[1,2,3,9,12,13]$ :

$$
\begin{aligned}
& \sigma=0,025 x+1,028, \\
& \sigma=1,642 x+44,72, \\
& \sigma=3,480 x+913,6,
\end{aligned}
$$

позволяет сделать вывод, что в выемочном столбе, на штреках и в демонтажной камере горное давление имело знакопеременный характер. Была выявлена тенденция к его снижению. Это 


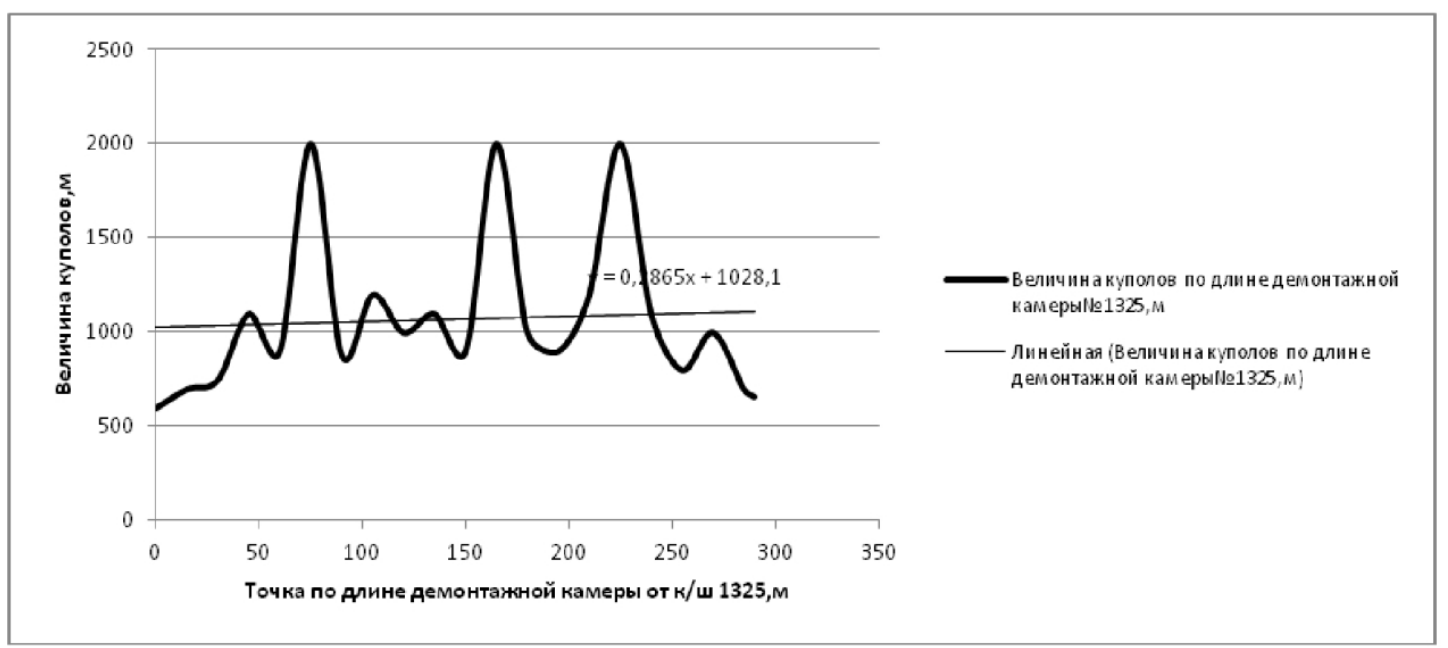

Рис.6.Распределение образования куполов по длине демонтажной камеры № 1325 от конвейерного штрека № 1325. Угол падения $2^{\circ}$

Fig. 6. Distribution of dome formation along the length of dismantling chamber No.1325 from conveyor gate No. 1325. The angle of inclination is $2^{\circ}$
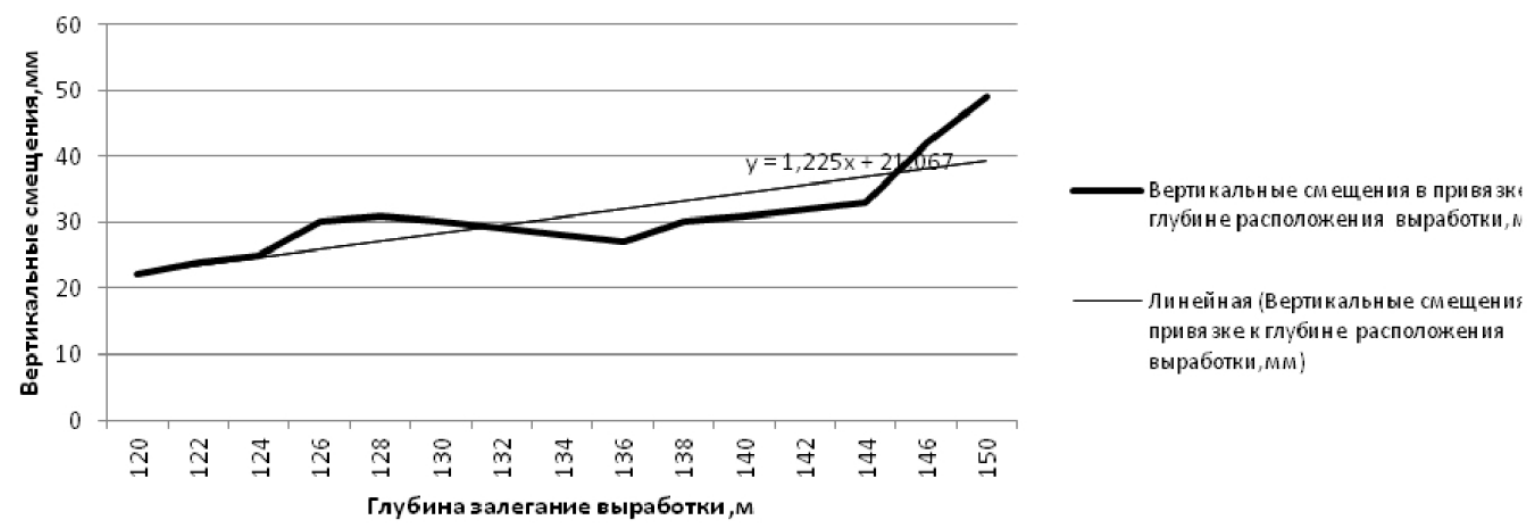

Рис.7. График проявления вертикальных смещений на в/и № 1362 при изменении глубины заложения выработки от 120 до 150 м. Угол падения $3^{\circ}$

Fig. 7. The scheme of vertical displacement at air gate No.1362 at a change of the depth of the gate development from $120 \mathrm{~m}$ to $150 \mathrm{~m}$. The angle of seam inclination is $3^{\circ}$

способствовало уменьшению высоты куполов до 2 м. С увеличением глубины залегания пласта и в связи с наличием значительных площадей ЗПГД давление возрастало.

Демонтажная камера № 1362

Длительный срок поддержания камеры явился причиной ухудшения прочностных характеристик деревянного перекрытия, его разрушения при извлечении секций крепи, значительного куполообразования и увеличения сроков демонтажа до 65 дней.

График вертикальных смещений пород кровли и почвы на в/ш № 1362 в зависимости от глубины заложения выработки изображен на рис. 7.

В итоге наблюдения показали, что процесс подготовки Д.К. и последующий период до начала демонтажа не сопровождались: увеличением нагрузки на крепь, деформациями крепи выработки, отслоением пород, отжимом в бортах.Это подтверждается незначительными смещениями - (22-
49) мм. Величина смещений пород кровли и почвы в/ш № 1362 по всей длине выработка оображена на рис. 8.

Анализируя данные графика, можно сделать вывод, что при приближении к ЗПГД и к демонтажной камере величина смещений увеличивалась. Это объясняется повышением напряженного состояния горного массива в этих зонах.

Распределение куполообразования по длине демонтажной камеры № 1362 от в/ш № 1362, угол падения $5^{\circ}$ отображено на рис. 9 .

Анализ графиков (рис.7,8,9) и рассчитанных зависимостей проявления опорного давления формулы $(7,8,9)[1,2,3,9,12,13]$ :

$$
\begin{aligned}
& \sigma=1,225 x+21,06, \\
& \sigma=1,3535 x+31,56, \\
& \sigma=37,72 x+510,
\end{aligned}
$$

показывает, что в выемочном столбе, на штреках и в ДК горное давление имело знакопеременный характер и резко увеличивалось при подходе 
Вестник Кузбасского государственного технического университета. 2018. № 4, с.75-83

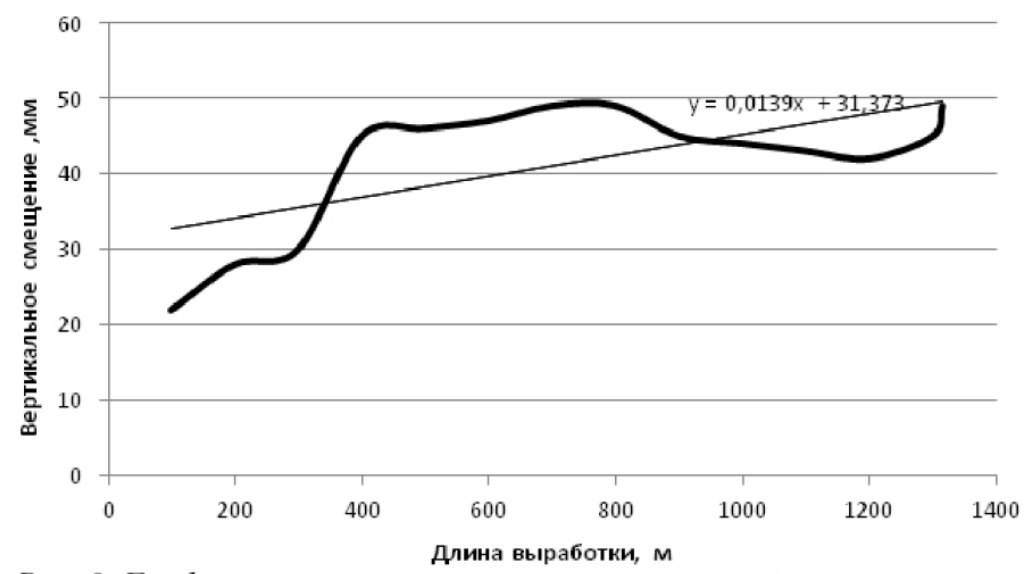

Вертикальныесмещения кровли в 1362 от устья до демонтажн ой кап $1362, \mathrm{Mm}$

- Линейная (Вертикальные смещен। кровли в в/ш 1362 от устья до дем он тажн ой кам еры 1362,мм)

Рис. 8. График проявления вертикальных смещений в кровле и почве по всей длине вентиляционного итрека №1362. Угол падения 2-4은

Fig. 8. The scheme of vertical displacement in the roof and floor along the length of air gate No.1362. The angle of seam inclination is 2 to $4^{\circ}$

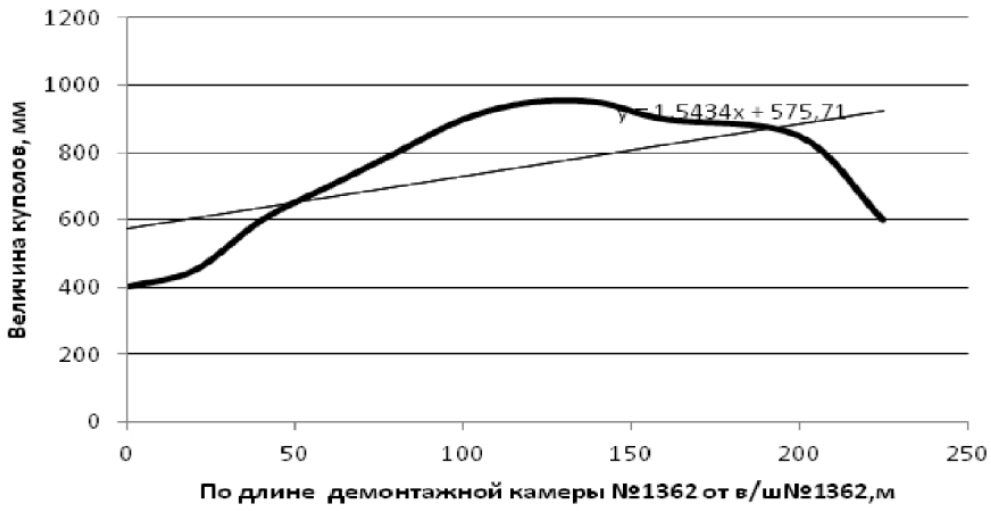

- Величинавыволов пород кровли дем онтажн ой камере №1362, м

- Линейная (Величина выволов пор кровли в демонтажной камере №1362, MM)

Рис. 9. Распределение образования куполов по длине демонтажной камеры № 1362 от в/ии № 1362. Угол падения $5^{\circ}$

Fig. 9. Distribution of dome formation along the length of dismantling chamber No.1362 from air gate No. 1362. The angle of inclination is $5^{\circ}$

Величина смещений пород кровли и почвы к/ш №1390 в привязке к глубине залегания выработки, $\mathrm{Mm}$

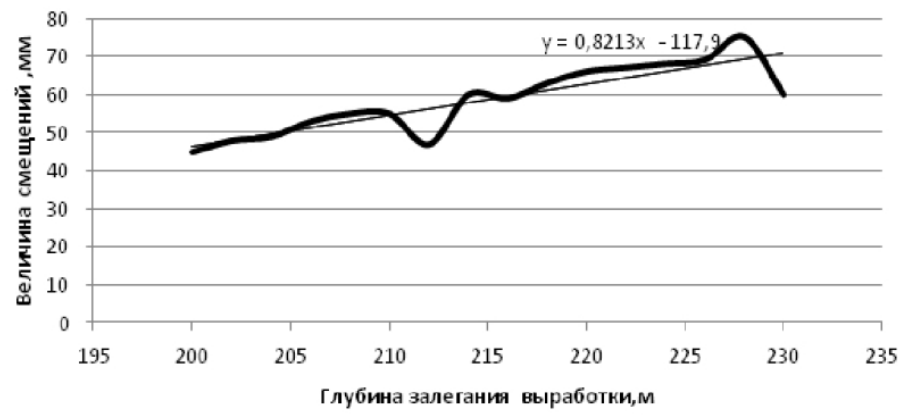

Величинасмещений пород кровли и почвы к/шґㅇ1390 в привякзкек глубине залегания выработки, $m$ м

— Линейн ая (Величина сиещений пород кровли и почвы $\mathrm{k} / \mathrm{wl} \mathrm{l} 1390$ в привякзкек глубине залегания выработки, мм

Рис. 10. График проявления вертикальных смещений на к/и № 1390 при изменении глубины заложения выработки, мм

Fig. 10. The scheme of vertical displacement in conveyor gate No.1390 with the change of the depth of the gate development, $\mathrm{mm}$ 


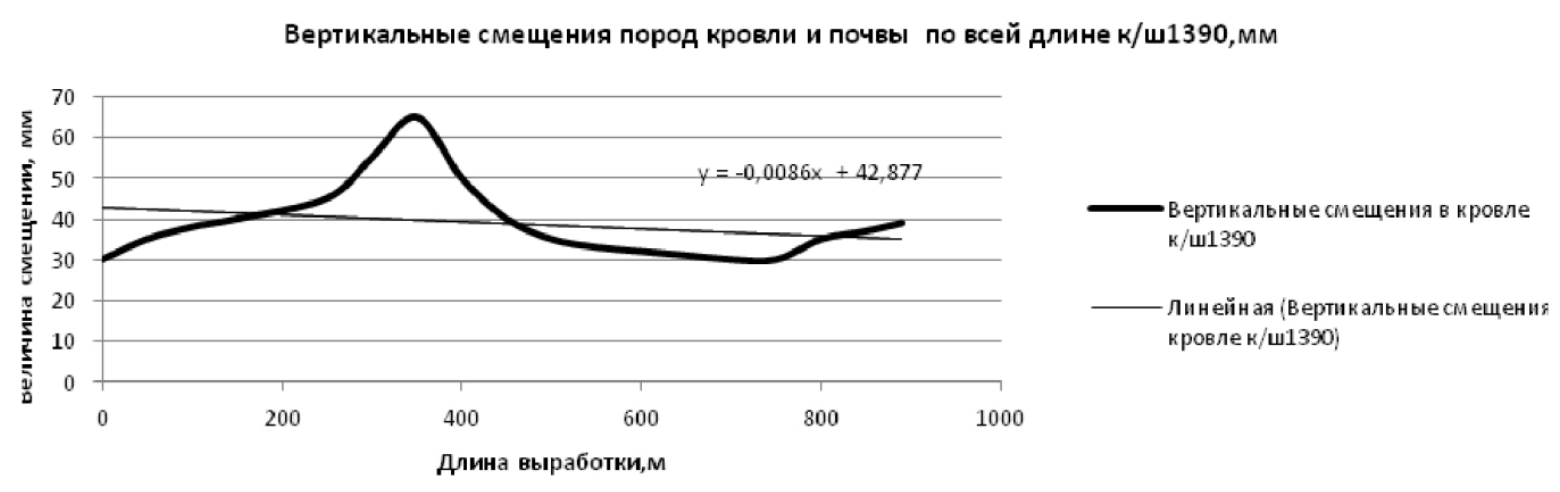

Рис.11. График проявления вертикальных смещений в кровле и почве по всей длине конвейерного итрека №1390. Угол падения $3^{\circ}$

Fig. 11. The scheme of vertical displacement in the roof and floor along the length of conveyor gate No.1390. The angle of seam inclination is $3^{\circ}$

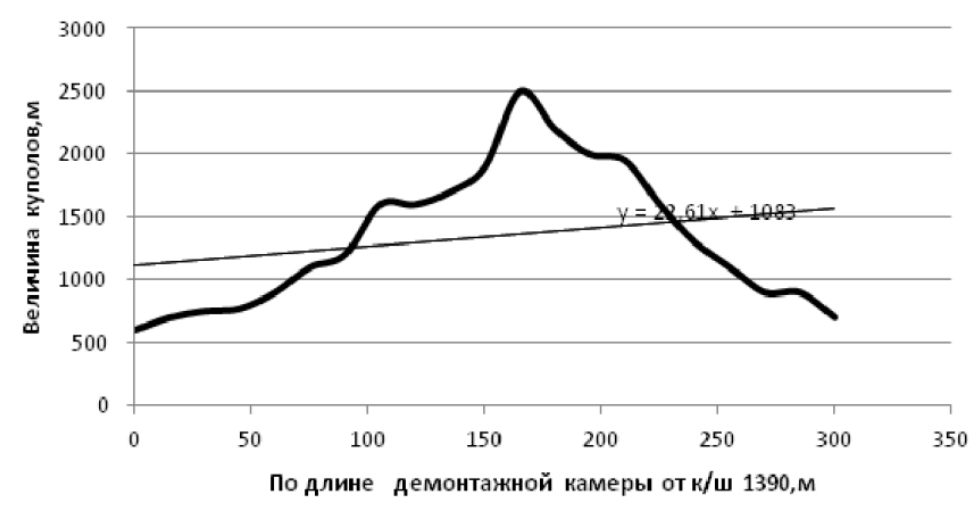

Величинакуполов по длинедемонтажн кам еры№1390, $\mathrm{m}$

- Линейная (Величина куполов по длине дем онтажн ой камеры№1390,м)

Рис. 12. Распределение образования куполов по демонтажной камере №1390, от конвейерного штрека № 1390. Угол падения $1^{\circ}$

Fig. 12. Distribution of dome formation along the dismantling chamber No.1390 from conveyor gate No. 1390. The angle of inclination is $1^{\circ}$

лавы к зонам ПГД. Кроме того проявлялась положительная корреляционная связь его увеличения с глубиной залегания выработки. В демонтажной камере № 1362 опорное давление проявило себя, при подходе лавы значительным куполообразованием в середине демонтажной камеры, при последующем постепенном снижении объемов вывалов к штрекам.

\section{4. Демонтажная камера №1390}

При ведении демонтажных работ вывалы породы носили локальный характер. Высота куполов не превышала 2 м. Это свидетельствует об устойчивом состоянии приконтурного массива и незначительном расслоении пород непосредственной кровли.

График вертикальных смещений пород кровли и почвы на к/ш № 1390 в зависимости от глубины заложения выработки изображен на рис. 10.

Анализ графика показывает, что смещения изменяются в пределах 45-75 мм. Минимум наблюдался при выходе из ЗПГД, максимум к зонам формирования опорного давления у сбоек ДК № 1390 .
Вертикальные смещения пород кровли и почвы по всей длине к/ш 1390, мм представлены на рис. 11.

Максимально активное обрушение пород кровли с образованием куполов по демонтажной камере №1390 происходило в средине выработки. На сопряжениях демонтажной камеры со штреками подобных явлений не наблюдалось (рис. 12).

Анализ графиков (рис. 10, 11, 12) и рассчитанных зависимостей проявления опорного давления формулы $(10,11,12)[1,2,3,9,12,13]$ :

$$
\begin{aligned}
& \sigma=1,642 x+44,72, \\
& \sigma=-0,505 x+43,69, \\
& \sigma=22,61 x+1083,
\end{aligned}
$$

позволяет сделать вывод, что в выемочном столбе лавы, на штреках и в демонтажной камере горное давление имело знакопеременный характер. Наблюдалась тенденция к его снижению по длине выработки, однако при подходе к зонам ПГД зафиксировано резкое повышение. Оно возрастало и с увеличением глубины залегания выработки. При подходе очистного забоя к демонтажной камере на $70 \%$ её протяжённости наблюдалось интенсивное обрушение пород кровли и куполообразование,. Причём наиболее активно в 
средине камеры.

Для решения поставленной задачи, используя гипотезу плит, определим показатели опорного давления (нагрузки), возникающего в исследуемых демонтажных камерах [1-6,9,12-15]. Определяя величины констант, используемых в формулах (1-12), рассчитаем нагрузки в демонтажных камеpax, т.к. именно в них, происходит куполообразование, что значительно усложняет процесс демонтажа оборудования.

Максимальная интенсивность нагрузки для ДК зависит от угла обрушения, изменяющегося в пределах $\delta=60-85^{\circ}$, и определяется по формуле:

$$
q_{\mathrm{H}}=0,5 \gamma_{\mathrm{cp} .} \operatorname{ltg} \delta
$$

$$
q_{\mathrm{H}}=0,5 \cdot 2,3 \cdot 6 \cdot \operatorname{tg} 60^{\circ}=11,73 \mathrm{~T} / \mathrm{M}^{2}
$$

Максимальная величина $C_{q}$ - опускание среднего шарнира при соответствующих $q_{\mathrm{H}}=11,73$ и пределе прочности непосредственной кровли $\sigma_{\text {пч.сж. }}=40-50$ МПа определяется по формуле:

$$
C_{q}=h_{\mathrm{H}}-\frac{q_{\mathrm{H}} l^{2}}{4 k h_{\mathrm{H}} \sigma_{\text {пч } . c \%}}
$$

где $k$ - безразмерный коэффициент, получаемый опытным путем $(k=0,4) ; h_{\mathrm{H}}-$ мощность непосредственной кровли $\left(h_{\mathrm{H}}=4 \mathrm{м}\right)$. Тогда $C_{q}=$ 2,35 м., что вполне соответствует средним величинам высоты куполов в исследуемых ДК №№ $1324,1325,1362,1390$.
Таким образом, учитывая факты проявления горного давления в ДК №o 1324, 1325, 1362, 1390, по результатам проведенного анализа их подготовки, можно сделать следующие выводы:

1. При заблаговременной подготовке ДК в результате повышенного горного давления, в породах непосредственной и основной кровли пласта, над заранее пройденной выработкой, происходит расслоение пород;

2. При расчете крепи ДК не учитывается величина опорного давления от приближающегося очистного забоя;

3. Отсутствует необходимые измерения величины максимального опорного давления впереди очистного забоя и шага обрушения основной кровли. Существующие методики расчета шага обрушения основной кровли не дают точного результата из-за разнообразия горно-геологических условий;

4. Формирование демонтажной камеры очистным забоем является наиболее приемлемым вариантом;

5. Для более точного определения шага обрушения кровли и нагрузки на перекрытия секций необходимо оснащать все приобретаемые мехкомплексы автоматизированной системой контроля воздействия горного давления на элементы крепи.

\section{СПИСОК ЛИТЕРАТУРЫ}

1. Указания по управлению горным в очистных забоях под (над) целиками и краевыми частями при разработке свиты пластов мощностью до 3,5 м и с углом падения до $35^{\circ}$.Ленинград : ВНИМИ, 1984. - 59 c.

2. Борисов, А.А. Механика горных пород и массивов. - М. : Недра, 1980. - 360 с.

3. Черняк, И.Л. Управление горным давлением в подготовительных выработках глубоких шахт / И. Л. Черняк, Ю. И. Бурчаков - М. : Недра, 1984. - 304 с.

4. Слесарев В. Д. Определение оптимальных размеров целиков различного назначения - М. : Углетехиздат, 1948.

5. Бублик, Ф.П. К вопросу определения нагрузки на предохранительные и барьерные целики / Ф. П. Бублик, Г. А. Иванов, А. В. Плахов // Уголь. 1974. - № 2. - С. 3-5.

6. Гмошинский В.Г. Горное давление на пологий угольный пласт в окрестности выработок. Уголь, 1957, № 6. - С 16-23.

7. Климов, В.В. Исследование влияния опорного давления, формируемого очистным забоем на состояние прилегающих горных выработок в условиях отработки угольных пластов средней мощности на шахтах OAO «СУЭК-Кузбасс» как в нисходящем, так и в восходящем порядке на примере отработки запасов угля в границах шахтного поля шахты «Полысаевская» / В. В. Климов, А. В. Ремезов // Вестник PAEH ЗСО - выпуск 15. 2013. - С. 30-38.

8. Горное давление. Его проявления при ведении горных работ в массиве горных пород / А. В. Ремезов, И. К. Костинец, В. Г. Харитонов, Н. В. Рябков, А. И. Жаров, В. В. Климов, И. Л. Харитонов, С. В. Новоселов / Кемерово. - 2013. - 681 с.

9. Геомеханика / П. В. Егоров, Г. Г. Штумпф, А. А. Ренев [и др.] // Гос. учреждение Кузбас. гос. техн. ун-т. - Кемерово. 2002. - 339 с.

10. Рациональные способы и средства охраны выемочных выработок в очистных забоях / М.И. Середенко, А.П. Егоров, А.В. Ремезов и др. // Технологические процессы и механизация отработки угольных пластов Кузбасса: Сб. науч. тр. / КузНИУИ. - Прокопьевск, 1990. - С. 157-164.

11. Ремезов А.В. Исследования проявления горного давления при работе спаренных лав на шахте «Октябрьская» ПО «Ленинскуголь» / А.В. Ремезов, Ю.Г. Зельцер, А.М. Бонин // Совершенствование тех- 
нологии отработки угольных месторождений Кузбасса: Сб. науч. тр. / Ассоциация «Кузбассуглетехнология». - Кемерово, 1991. - С. 108-115.

12. Беляев, А.М. Сопротивление материалов. - М. : Недра, 1965. - 856 с.

13. Oskar Jacobi. Praxis der Gebirgsbeherrschung - Vertag Gluckauf GmbH, Essen, 1981. - 568 s.

14. Knissel W., Linzig H. J. Verlegung der Abbaustrecken drukentlastete Zonen. Steinkohlenbergverk der Zukunft. - Essen, Bergbau-Forschung, 1977.

15. Leonhardt J. Vorlaufige Richtlinein zur Anwendung des Prallhammers. - Mitt. Aus dem Markscheidewesen, 1965, Bd. 72, S. $127-139$.

\section{REFERENCES}

1. Directions for to management mountain in breakage faces under (over) pillars and regional parts by working out of retinue of seams by power to $3,5 \mathrm{~m}$ and with an angle of incidence to $35^{\circ}$. Leningrad: LISTEN, 1984. $-59 \mathrm{p}$.

2. Borisov, A.A. Rock mechanics and files. - M: Bowels, 1980. - 360 p.

3. Chernjak, I.L. management a rock pressure in development openings of deep pits / I. L. Chernjak, Ju. I. Burchakov - M: Bowels, 1984. - 304 p.

4. Slesarev V. D. Definition of optimum sizes it is whole of different function - M: Ugletehizdat, 1948.

5. Bublik, F. P. To a question of definition of loading on safety and barrier pillars / F. P. Bublik, G.A.Ivanov, A. V.Plahov//Coal. 1974. - № 2. - p. 3-5.

6. Gmoshinsky V. G. Rock pressure on a flat coal seam in a neighbourhood of developments. Coal, 1957, № 6. - P 16-23.

7. Klimov, V.V. Issledovanie of agency of the bearing pressure formed by a breakage face on a condition of adjoining mine workings in the conditions of working off of coal seams of average power on pits of Open Society "SUEK-KUZBASS" both in descending, and in an ascending order on an instance of working off of stocks of coal in boundary lines of a mine field of pit «Polisaevsky» / V.V.Klimov, A. V.Remezov//the Bulletin of Russian Academy of Natural Sciences ZSO - exhaustion 15. 2013. - p. 30-38.

8. A rock pressure. Its developing processes at conducting mountain works in a rock mass / A. V.Remezov, I.K.Kostinets, V.G.Haritonov, N. V.Rjabkov, A.I.Zharov, V.V.Klimov, I.L.Haritonov, S. V.Novoselov / Kemerovo. - 2013. $-681 \mathrm{p}$.

9. Geomechanics / P.V.Egorov, G.G.Shtumpf, A.A.Renev [etc.]//State Establishment Kuzbas. The state technical university. - Kemerovo. 2002. - 339 p.

10. Rational ways and means of protection of developments in breakage faces / M.I.Seredenko, A.P.Egor, A.V.Remezov, etc.//Processes and mechanisation of working off of coal seams of Kuzbas: the Collector of proceedings / KuzNIUI. - Prokopevsk, 1990. - p. 157-164.

11. Remezov A.V.research of a rock pressure manifestation at work of the paired walls on pit «October« ON "Leninskugol" / A.V.Remezov, JU.G.Zeltzer, A.M.Bonin//Perfection of production engineering of working off of coal deposits of Kuzbas: the Collector of proceedings / Association « Kuzbassugleteshnologija». - Kemerovo, 1991. - p. 108-115.

12. Beljaev A. M. Resistance of materials. - M: Bowels, 1965. - 856 p.

13. Oskar Jacobi. Practice Gebirgsbeherrschung - Vertag Gluckauf GmbH, meal, in 1981. - 568 p.

14. Knissel watt., Linzig C.Dzhoul. A lining of extraction galleries drukentlastete zones. Steinkohlenbergverk the future. - meal, mineral industry research, in 1977.

15. Leonhardt J. Vorlaufige Richtlinein to a rock bump explanation. - Mitt. From mine surveying, in 1965, T. 72 , p. $127-139$. 